\title{
A VALIDADE JURÍDICA DE ACORDOS DE PESCA FORA DE ÁREAS PROTEGIDAS: UMA ANÁLISE DO SETOR CAPIVARA, NO MUNICÍPIO DE MARA Ã, AMAZONAS
}

\section{LA VALIDITE JURIDIQUE DES ACCORDS DE PECHE DN DEHORS DES ZONES PROTEGEES : L'ANALYSE DE LACCORD DE PECHE DANS SECTEUR CAPIVARA, LA MUNICIPALITE DE MARÃ̃, ETAT D'AMAZONAS}

\author{
${ }^{1}$ Juliana de Carvalho Fontes \\ ${ }^{2}$ Marcelo Pires Soares
}

\section{RESUMO}

A presente pesquisa tem por objetivo investigar a validade jurídica de acordos de pesca fora de áreas protegidas contra terceiros não participantes, a partir da análise do Acordo de Pesca do Setor Capivara, no Município de Maraã, Estado do Amazonas. Há bastante tempo, acontecem na região amazônica conflitos socioambientais pesqueiros, envolvendo diferentes grupos sociais. Como solução, foram instituídos acordos de pesca, os quais fixam regras de acesso, uso, fiscalização e punição, para o controle da pesca em determinada localidade. Entretanto, como ocorre no Acordo de Pesca do Setor Capivara, alguns grupos sociais tendem a opor resistência a estes acordos, seja porque não participaram dele quando da elaboração, seja porque a localidade não se insere em uma unidade de conservação ou espaço especialmente protegido pelo poder público. A resposta a este problema está na compreensão da nova estrutura do Estado moderno e dos direitos coletivos. Pela visão contratualista clássica, os contratos são marcados pela relatividade, onde apenas as partes estão vinculadas ao cumprimento de suas disposições. Porém, os acordos de pesca, mesmo fora de áreas protegidas, materializam direitos coletivos reais, de titularidade plural, como a preservação do meio ambiente ecologicamente equilibrado e a proteção dos conhecimentos tradicionais, e criam indiscutivelmente limitações a direitos individuais, sendo inadequado seu entendimento a partir do pensamento contratualista. Por tal motivo, o Acordo de Pesca do Setor Capivara deve ser considerado como válido contra terceiros dele não participantes. $\mathrm{O}$ método científico adotado é o da pesquisa bibliográfica qualitativa.

Palavras-chave: Acordos de pesca, Áreas ambientalmente protegidas, Validade jurídica, Direitos coletivos, Setor capivara

\section{RESUMEN}

Cette recherche vise à enquêter sur la validité juridique des accords de pêche en dehors des zones protégées de la non-participant tiers, de l'analyse de lAccord de Pêche dans Secteur Capivara, la municipalité de Maraã, État d'Amazonas. Pendant longtemps, il ya des poissons dans les conflits environnementaux de la région amazonienne, impliquant les différents groupes sociaux. Comme solution, les accords de pêche ont été mis en place, qui a fixé des règles pour l'accès, l'utilisation et l'inspection, le contrôle de la pêche dans une localité

\footnotetext{
1 Mestranda em Direito Ambiental da Universidade do Estado do Amazonas. Instrutura de Penal Militar e Processo Penal Militar nos cursos de formação da Força Aérea Brasileira. Universidade do Estado do Amazonas UEA/AM, Amazonas. Brasil - E-mail: julicfontes@gmail.com

2 Mestrando em Direito Ambiental da Universidade do Estado do Amazonas. Juiz Federal Titular da 1a Relatoria da Turma Recursal dos Juizados Especiais Federais dos Estados do Amazonas e Roraima. Universidade do Estado do Amazonas - UEA/AM, Amazonas. Brasil - E-mail: 1982marcelo@gmail.com
} 
donnée. Cependant, comme dans l'Accord de Pêche dans Secteur Capivara, certains groupes de pêcheurs ont tendance opposer la force, car en plus de ne pas avoir l'impliquer quand rédigé, la région ne tombe pas dans une zone ou un espace protégé par le pouvoir public. La réponse à ce problème réside dans la compréhension de la nouvelle structure de l'Etat moderne et les droits collectifs. En vue contractualiste classique, les contrats sont marqués par la relativité, où seules les parties sont tenues de se conformer à ses dispositions. Cependant, les accords de pêche, même en dehors des zones protégées, matérialisent droits collectifs, de propriété plurielle, tels que la préservation d'un environnement écologiquement équilibré et de la protection des savoirs traditionnels, et créent sans doute limitations aux droits individuels, et inappropriée leur compréhension de la pensée contractualiste. Par conséquent, l'Accord de Pêche dans Secteur Capivara devrait être considéré comme opposable aux tiers ne participant pas à elle. La méthode scientifique adoptée est la littérature qualitative.

Mots-clés: Les accords de pêche, Les zones écologiquement protégées, La validité juridique, Droits collectifs, Secteur capivara 


\section{INTRODUÇÃO}

A região amazônica, objeto de cobiça e interesses por causa de seu vasto volume hidrográfico e sua grande sociobiodiversidade, requer uma análise minuciosa quanto às suas políticas públicas e regulações, sobretudo no setor pesqueiro.

A área da pesca fornece uma fonte vital de alimento, emprego, lazer, comércio e bem-estar econômico para as gerações presentes e futuras. Ao constituir um patrimônio gerencial, é preciso reconhecer que o seu manejo seja enquadrado por critérios de sustentabilidade.

Nesse contexto, surgem os acordos de pesca que, já utilizados anteriormente em outros países, aparecem na Amazônia a partir da década de 70, como uma forma diferenciada de gestão dos recursos pesqueiros.

Em junho de 2014, a Secretaria do Estado do Meio Ambiente e Desenvolvimento Sustentável do Amazonas, através da Instrução Normativa SDS n. 03/2014, reconheceu o Acordo de Pesca do complexo de lagos do Paraná do Jacaré, Setor Capivara, no Município de Maraã, Amazonas.

Este Acordo de Pesca, assessorado pelo Instituto Mamirauá, significa um grande desafio na gestão dos estoques pesqueiros. Isso porque, ao contrário de outros acordos, a abrangência territorial deste complexo de lagos localiza-se fora de uma área protegida pelo poder público.

A Constituição Federal, no interesse de preservar o meio ambiente, impõe ao poder público o dever de instituir espaços territoriais especialmente protegidos, como são as unidades de conservação, então delimitadas e submetidas a um regime especial de administração.

Porém, nem sempre o Estado é rápido o suficiente para instituir essas áreas ambientalmente relevantes. Muitas vezes as populações locais, pressionadas pela exploração desenfreada, em constantes conflitos socioambientais, reúnem-se e estabelecem regras para utilização sustentável dos recursos naturais.

É o caso do Acordo de Pesca do Setor Capivara, cuja Instrução Normativa que o reconheceu, define regras de acesso, uso, vigilância e monitoramento dos ambientes aquáticos nele contemplados, mediante parceria entre os órgãos públicos ambientais e a sociedade civil.

Entretanto, alguns grupos de pescadores, sobretudo os urbanos e comerciais, tendem a opor resistência ao Acordo de Pesca, porque, além de não terem dele participado, não se 
sentem vinculados às regras de acesso e uso, já que não se trata de um espaço especialmente protegido pelo poder público.

Nesse cenário, chega-se à questão principal deste trabalho: há validade jurídica no Acordo de Pesca no Setor Capivara contra terceiros, embora fora de uma área protegida pelo Estado e não sujeita a um regime especial anterior?

A solução do problema passa pela compreensão da nova estrutura do Estado moderno, dos direitos coletivos e sua titularidade plural, impondo-se romper com a cultura contratualista, em que só se admitem efeitos vinculantes entre as partes, e da dicotomia entre público e privado.

A relevância da pesquisa decorre da discussão sobre o uso sustentável dos recursos pesqueiros, tema este tão caro à região amazônica, geralmente inserido em um campo de incerteza ou mesmo de desconhecimento jurídico. O trabalho permitirá ainda conhecer a estrutura dos acordos de pesca, em especial o do Setor Capivara.

O objetivo principal é investigar a validade jurídica dos acordos de pesca fora de áreas protegidas contra terceiros não participantes. Secundariamente, os objetivos são estudar os acordos de pesca, em seu conceito, características e regras; contextualizá-los na região amazônica; e compreender a dimensão dos direitos coletivos.

O método científico adotado é a pesquisa bibliográfica qualitativa.

\section{A LEGISLAÇÃO PESQUEIRA}

Não há como iniciar o estudo do tema sem antes fazer um breve apanhado da legislação pesqueira e de sua posição dentro da dogmática jurídica.

Como explica Camargo et al (2012, p. 19), o Direito de Pesca não constitui um ramo autônomo do Direito, porque não tem autonomia epistemológica nem princípios próprios. Hoje o Direito de Pesca tem sua base no Direito Agrário, conforme se percebe da Constituição Federal, que, no seu artigo $187, \S 1^{\circ}$, inclui entre o planejamento agrícola as atividades agroindustriais, agropecuárias, pesqueiras e florestais.

A Constituição Federal, no artigo 23, preconiza que é atribuição de todos os entes da Federação a proteção do meio ambiente e a preservação das florestas, da flora e da fauna, aí inseridos os recursos pesqueiros. O artigo 24, inciso VI, traz a competência concorrente da União, dos Estados e do Distrito Federal, para legislar sobre pesca, conservação da natureza e proteção do bem ambiental, podendo também os municípios fazê-lo, na forma do artigo 30, para suplementar a legislação federal e estadual. 
A Lei 11.959, de 29 de junho de 2009, define a Política Nacional de Desenvolvimento Sustentável da Aquicultura e da Pesca, para tratar sobre as atividades pesqueiras. $\mathrm{O}$ artigo $3^{\circ}$ dessa Lei impõe ao poder público o dever de conciliar o equilíbrio entre o princípio da sustentabilidade dos recursos pesqueiros e a obtenção de melhores resultados econômicos e sociais.

Assim, os objetivos da Política Nacional de Pesca, conforme Camargo et al (2012, p. 21), são:

\begin{abstract}
o desenvolvimento sustentável da pesca como fonte de alimentação, emprego, renda e lazer, garantindo-se o uso sustentável dos recursos pesqueiros, visando também a otimização dos benefícios econômicos decorrentes, em estreita harmonia com a preservação e a conservação do meio ambiente e da biodiversidade; o ordenamento, o fomento e a fiscalização de toda a atividade pesqueira; a preservação, a conservação e a recuperação dos recursos pesqueiros e dos ecossistemas aquáticos; e, por fim, o desenvolvimento socioeconômico, cultural e profissional dos que exercem a atividade pesqueira, bem como de suas comunidades.
\end{abstract}

Por sua vez, o artigo $8^{\circ}$ da Lei $11.959 / 2009$ classifica a pesca em comercial e não comercial. A primeira corresponde à pesca artesanal, praticada por pescador profissional, de forma autônoma ou em regime de economia familiar, e à industrial. A pesca não comercial divide-se em científica, amadora e de subsistência, sendo que esta última tem por fim o consumo doméstico ou escambo sem fim lucrativo.

Outro diploma do Direito de Pesca é a Instrução Normativa n. 29, de 31 de dezembro de 2002, do Instituto Brasileiro do Meio Ambiente e dos Recursos Naturais Renováveis (IBAMA), que estabelece os critérios para a regulamentação de acordos de pesca em uma determinada comunidade pesqueira. $\mathrm{O}$ artigo $1^{\circ}$ da referida Instrução fixa as características principais e o conceito dos acordos de pesca, enquanto o artigo $2^{\circ}$, os procedimentos para a sua regulamentação.

\title{
2 OS ACORDOS DE PESCA
}

Os rios, lagos e igarapés são muito importantes para quem mora nas suas margens. Afinal, é dali que saí o sustento, como o peixe, sua fonte principal de alimento e de renda. Por isso, é preciso cuidar bem desses recursos que a natureza oferece gratuitamente para todos.

Por causa da pesca sem controle, muitas espécies correm o risco de desaparecer, como é o pirarucu, espécie sobre-explotada e de grande importância na Amazônica, impondose o manejo. Manejar a pesca significa controlar a captura de peixes para que exista um equilíbrio entre a reprodução e extração pelo homem desse bem ambiental. 
O manejo traz vantagens para os pescadores, pois garantem a captura do peixe por mais tempo, bem como para o meio ambiente, uma vez que a boa administração da pesca respeita a capacidade de recuperação do estoque pesqueiro e mantém a vida de diversos animais que se alimentam e se reproduzem nesses ambientes.

Nesse contexto, ganham também as pessoas que vendem o pescado manejado, pois, ao demonstrar o interesse na preservação ambiental, conquistam confiança do mercado, o qual, por sua vez, ao comprar um peixe de área manejada, ajuda a conservar o meio ambiente e a melhorar a qualidade de vida das populações ribeirinhas.

Entretanto, estas relações não são tão pacíficas quanto parecem ser. Acontecem há anos vários conflitos socioambientais pesqueiros na região Amazônica. Como esclarece Aguiar (2009, p. 289), esses conflitos envolvem fazendeiros, pescadores urbanos, pescadores artesanais, comerciantes e o próprio Estado. Não há uma homogeneização ou bipolarização.

A pesca comercial predatória e os interesses econômicos significam uma ameaça aos estoques pesqueiros e às populações ribeirinhas, notadamente em áreas não protegidas pelo poder público, onde não existe um regime especial de administração para limitar os usos e estabelecer regras de manejo.

Esses conflitos socioambientais decorrem da própria escassez que caracteriza os recursos pesqueiros na Amazônia. Explica Aguiar (2009, p. 286):

\footnotetext{
Estes conflitos são causados por vários fatores, como o crescimento de demanda para compra e comercialização de pescado. Dentre todas estas situações há os recursos pesqueiros, que quando não manejados e sobre-explotados ficam escassos e com isso, falta alimentação das famílias das comunidades tradicionais e para a subsistência dos pequenos pescadores. Outro fator que contribui para a sobreexplotação dos recursos pesqueiros é a modernização das técnicas de pesca, que facilita a atividade, onde antes não havia possibilidade do seu exercício.
}

Como solução a esses conflitos socioambientais, são elaborados acordos de pesca, que consubstanciam ajustes coletivos, fundados em práticas costumeiras e destinados a regulamentar a exploração sustentável dos recursos pesqueiros em determina comunidade, em proteção aos pescadores ribeirinhos.

\subsection{Histórico}


As populações humanas que habitam as áreas de várzea amazônica tem desenvolvido há décadas uma expressiva relação de exploração dos recursos naturais, direcionada, sobretudo, aos recursos pesqueiros, incluindo quelônios, peixes e vegetais aquáticos.

Embora a oferta de recurso pesqueiro seja historicamente abundante na região amazônica e o pescado seja considerado a principal fonte de abastecimento alimentar, mudanças importantes relacionadas ao setor aconteceram nas últimas décadas.

No final do século XX, a pesca comercial e sua capacidade de captura cresceram significativamente na Amazônia com a introdução dos motores a diesel (que possibilitaram alcançar áreas mais distantes em menor tempo), das fibras de náilon para redes (que implicaram a disseminação das redes de fibra sintética e mudanças no esforço de pesca) e do polietileno, que possibilitou o uso de caixas com melhor isolamento térmico e do gelo para conservar o pescado.

Além disso, a partir dos anos 1960, o declínio de muitas atividades econômicas, como a exploração da borracha e da juta, fez com que a pesca passasse a ser uma das principais atividades geradoras de renda para as famílias ribeirinhas, mas, ao mesmo tempo, trouxeram um inchaço para o setor, uma vez que muitas pessoas desempregadas passaram a migrar para essa atividade.

Este aumento da intensidade da pesca de espécies de água doce tem levado, não somente à alta explotação de algumas espécies de alto valor econômico, a exemplo do pirarucu e do tambaqui, mas também tem contribuído para o aumento dos conflitos entre pescadores comerciais, de subsistência, artesanais e do setor industrial.

Paralelamente, o aumento das populações ribeirinhas, o desmatamento e a degradação de ecossistemas vêm demandando políticas públicas que visem a uma gestão sustentável dos recursos pesqueiros.

É sob tal perspectiva que nasce um modelo de regulamentação da atividade pesqueira com o escopo de mantê-la compatível com o desenvolvimento sustentável da região onde se encontra.

Os acordos de pesca, utilizados no exterior, como na União Europeia, têm sido largamente empregados na Amazônia desde a década de 70, ou seja, muito antes da Instrução Normativa IBAMA n. 29/2002, que regulamentou a matéria. O primeiro acordo construído foi o Acordo de Pesca do Pantaleão, na Reserva Amanã, no ano de 2006.

Este sistema de gestão ganhou força no contexto do movimento socioambientalista, que evidenciou a tendência no cenário político em reunir a conservação ambiental e 
conhecimentos tradicionais, como a etnoictiologia, que é o estudo dos conhecimentos tradicionais sobre ecologia, comportamento e sistemática de peixes.

Desde então vários acordos foram celebrados. Como destacado acima, eles surgem como alternativa de solucionar conflitos relacionados ao aproveitamento pesqueiro, estabilizando ou reduzindo a pressão sobre tais recursos. No entanto, ainda hoje, questiona-se a validade jurídica desses instrumentos, especialmente contra terceiros não participantes.

Os acordos comunitários de pesca na Amazônia são um exemplo do sistema de gestão participativa, que criou mecanismos para a recepção de práticas de manejo e conhecimentos locais.

Constituem o foco principal de projetos de cooperação técnica, como o Projeto Aproveitamento dos Recursos Naturais de Várzea - PróVárzea e o Projeto Administração dos Recursos Pesqueiros do Médio Amazonas - IARA, executado pelo IBAMA.

\subsection{Conceito e Procedimentos}

Os acordos de pesca constituem uma das experiências mais interessantes de manejo de recursos pesqueiros controlados por populações ribeirinhas e, mais particularmente, em águas interiores e regiões de várzeas da Amazônia.

São normas criadas pelos grupos de usuários (comunidades, colônias e sindicatos) reconhecidos pelos órgãos de fiscalização, para o controle da pesca em determinada região. Os pescadores, que irão usufruir dos recursos pesqueiros, definem as normas que vão fazer parte do acordo, regulando a pesca de acordo com os interesses do grupo e com a conservação dos estoques pesqueiros.

De acordo com o artigo $1^{\circ}$, parágrafo único, da Instrução Normativa IBAMA n. 5 de 26/03/2008, entende-se por acordos de pesca "um conjunto de medidas específicas decorrentes de tratados consensuais entre os diversos usuários e o órgão gestor dos recursos pesqueiros em uma área definida geograficamente".

O Anexo I da referida Instrução Normativa detalha os procedimentos para o estabelecimento de um acordo de pesca, que se dividem em nove etapas, nessa ordem: mobilização, reuniões comunitárias, assembleia intercomunitária, retorno das propostas discutidas e aperfeiçoadas para as comunidades, assembleias intercomunitárias, encaminhamento para o IBAMA, divulgação da portaria, monitoramente e avaliação.

Desse modo, os acordos de pesca são regras que devem refletir os interesses coletivos das pessoas que pescam nas áreas em que foram instituídos, como pescadores 
comerciais, de subsistência e ribeirinhos. Deverão também manter a exploração sustentável dos recursos pesqueiros e, assim, valorizar a atividade de pesca e o pescador.

\title{
2.3 Características
}

O artigo $1^{\circ}$ da Instrução Normativa IBAMA n. 29/2002 define as características dos acordos de pesca a partir da percepção do que pode e do que não pode constar nestes instrumentos.

Os acordos de pesca precisam representar os interesses coletivos das pessoas atingidas, como os pescadores comerciais, de subsistência e os ribeirinhos, a fim de minimizar os conflitos socioambientais existentes, e assegurar a exploração sustentável dos recursos pesqueiros.

Devem também apresentar condições operacionais, principalmente quanto à fiscalização das áreas, sob pena de restar inócuos, e estar disciplinados em portarias normativas do IBAMA, o que confere a eles legitimidade estatal.

Por outro lado, os acordos de pesca não podem conceder privilégios de um grupo sobre outros, beneficiando somente algumas pessoas. Isso significa que as regras de uso impostas a um devem valer para todos, de modo que as restrições de apetrechos, tamanhos de embarcação e áreas protegidas sejam iguais.

Não devem conter regras de atribuição exclusiva do poder público, como imposição de multas e penalidades, para que não ocorra a indevida transferência para o particular.

Eis a redação do $\operatorname{artigo~} 1^{\circ}$ da Instrução Normativa IBAMA n. 29/2002:

\begin{abstract}
Art. $1^{\circ}$ Estabelecer os seguintes critérios para a regulamentação, pelo IBAMA, de Acordos de Pesca definidos no âmbito de uma determinada comunidade pesqueira: I) que sejam representativos dos interesses coletivos atuantes sobre os recursos pesqueiros (pescadores comerciais, de subsistência, ribeirinhos, etc.), na área acerca da qual se refere o Acordo, desde que não comprometam o meio ambiente enquanto patrimônio público a ser assegurado e protegido; II) que mantenham a exploração sustentável dos recursos pesqueiros, com vistas à valorização da pesca e do pescador; III) que não estabeleçam privilégios de um grupo sobre outros, ou seja, as restrições de apetrechos, tamanho de embarcação, áreas protegidas, etc, deverão ser aplicáveis a todos os interessados no uso dos recursos; IV) que tenham viabilidade operacional, principalmente em termos de fiscalização; V) que não incluam elementos cuja regulamentação seja atribuição exclusiva do poder público prevista em lei (penalidades, multas, taxas, etc); VI) que sejam regulamentados através de Portarias Normativas Complementares às Portarias de normas gerais que disciplinam o exercício da atividade pesqueira em cada bacia hidrográfica.
\end{abstract}

Todas essas características são refletidas e podem ser identificadas nos tipos de regras dispostos nos acordos de pesca. 


\subsection{Tipos de regras}

Os acordos de pesca compreendem quatro tipos de regras: regras de acesso, uso, punição e fiscalização. Esta classificação é apresentada por Dias (2012, p. 75). Cada grupo de regra permite contextualizar os acordos de pesca e analisar a validade jurídica perante os integrantes da comunidade envolvida e terceiros não participantes.

As regras de acesso levam em conta a verificação da residência de certa comunidade para admitir a pesca em uma região delimitada. Desse modo, uma comunidade poderia fixar as regras pesqueiras em uma área delimitada, excluindo terceiros estranhos, em atendimento a critérios de territorialidade e proximidade.

Os órgãos ambientais discordam desse tipo de regra, porque contraria a concepção do meio ambiente como bem coletivo, de interesse difuso e de uso comum de todos e viola a vedação de tratamento diferenciado entre os envolvidos. Por isso, são reduzidas ou não identificadas as regras de acesso nos acordos de pesca.

As regras de uso estão relacionadas ao modo como a pesca é praticada dentro de determinado espaço territorial delimitado, tratando da logística de produção, transporte, período do ano, tipos de peixes cuja pesca é permitida, e outras particularidades. Direcionam- se ao controle direto da atividade pesqueira comercial, mediante as práticas tradicionais das populações que definem as normas locais de utilização dos recursos.

Dias (2012, p. 81) contextualiza e esclarece a diferença entre as regras de acesso e de uso:

\footnotetext{
Neste sentido, surgem dois tipos de auto-regulamentação, feitas por estas comunidades pesqueiras, de modo a limitar a produção e os interesses individuais de forma a proteger o interesse coletivo: o de entrada limitada e o de cotas. No primeiro deles, a entrada no grupo de pescadores autorizados a ter acesso ao estoque de peixe é limitada, de forma que apenas os cooperados podem ter sua produção pesqueira. Por sua vez, o sistema de cotas estipula uma meta diária que não pode ser ultrapassada. Se houve pescadores que, porventura tenham ultrapassado sua cota, serão forçados a fazer a divisão com outros pescadores.
}

São necessárias, ainda, regras de fiscalização e punição, para garantir o êxito das regras de acesso e uso. As primeiras estão relacionadas ao monitoramento das áreas delimitadas objeto dos acordos, com a participação da comunidade e, principalmente, dos órgãos ambientais, que conferem maior força vinculante aos acordos, possibilitando que seus agentes realizem as fiscalizações.

As regras de punição compreendem a aplicação de penas (multas, perdimento e destruição de apetrechos) em razão do descumprimento das restrições impostas pelos acordos 
de pesca, sendo fundamental a participação dos órgãos ambientais, uma vez que estes instrumentos não podem contemplar diretamente sanções aos particulares, matéria esta de competência exclusiva do poder público.

\section{O ACORDO DE PESCA DO SETOR CAPIVARA NO MUNICÍPIO DE MARÃ̃}

Próximo à cidade de Tefé, interior do Estado do Amazonas, há um sistema de lagos de grande potencial, mas historicamente alvo da pesca predatória e de decréscimo do estoque pesqueiro. Em 2008, esta situação começou a mudar, quando pescadores ribeirinhos, pescadores urbanos de Tefé e instituições iniciaram a discussão para estabelecer um acordo de pesca.

Mesmo não abrangido por uma unidade de conservação ou área especialmente protegida, o Acordo de Pesca do Setor Capivara, no Município de Maraã, foi reconhecido pela Secretaria do Estado do Meio Ambiente e Desenvolvimento Sustentável do Amazonas, mediante a Instrução Normativa SDS n. 3, de 26 de junho de 2014, que compreende um complexo de lagos no Setor Capivara.

Como se verá, todos os tipos de regras expostos acima podem ser verificados no Acordo de Pesca do Setor Capivara.

É possível identificar-se as regras de uso nos artigos $3^{\circ}$ ao $6^{\circ}, 8^{\circ}$ e 11 , da Instrução Normativa SDS n. 3/2014, que estabelecem o modo como os recursos pesqueiros poderão ser utilizados, válidos para todos que pretendam fazer uso da área, agregando principalmente os conhecimentos das comunidades locais, no interesse de uma exploração sustentável dos recursos pesqueiros:

Art. $3^{\circ}$ Fica permitido aos pescadores:

I - Realizar a atividade de pesca desportiva 02 (duas) vezes por mês, entre os meses de agosto a outubro, respeitando a legislação vigente;

II - Levar até $10 \mathrm{~kg}$ de pescado, respeitando a legislação vigente;

Parágrafo único. Para essa modalidade fica permitido somente a pesca com caniço, corrico, linha de mão e flecha.

Art. $4^{\circ}$ Nos lagos de Manutenção a pesca poderá ser realizada com:

I - Utilização de 02 (duas) malhadeiras com malha entre $35 \mathrm{~mm}$ e $60 \mathrm{~mm}$, entre nós opostos, com no máximo 100 (cem) metros de comprimento, para cada pescador, respeitando a legislação vigente;

II - Utilização de caniço, tarrafa, linha de mão e zagaia;

III - Fica proibida a utilização de caixa de isopor superior a 50 litros na prática dessa atividade;

Art. $5^{\circ}$ Nos ambientes aquáticos destinados à pesca Comercial fica permitida a captura de peixe liso (bagre), respeitando a distância de 50 (cinquenta) metros da margem esquerda do Rio Solimões, da faixa que se estende da comunidade Caburini de Baixo até a comunidade São João. 
I - O apetrecho utilizado para a pesca do Pirarucu (Arapaima gigas) será a malhadeira com malha de no mínimo 30 (trinta) centímetros medidos entre nós opostos;

II - Paralelo à pesca do Pirarucu, acontecerá também a pesca do peixe miúdo, respeitando a legislação vigente;

III - A pesca do tambaqui fica permitida apenas na categoria de manutenção, utilizando malhadeira com malha mínima de 24 (vinte e quatro) centímetros medidos entre nós opostos, respeitando a legislação vigente;

Art. $6^{\circ}$ A pesca do peixe miúdo deverá ser realizada com os seguintes apetrechos: I - Aruanã (Osteoglossum bicirrhossum): malhadeira com malha mínima de 60 (sessenta) milímetros medidos entre nós opostos;

II - Tucunaré (Cichla spp.): malhadeira com malha mínima de 60 (sessenta) milímetros medidos entre nós opostos;

III - Peixe Liso (bagres): malhadeira com malha de 80 (oitenta) a 90 (noventa) milímetros, medidos entre nós opostos;

IV - Pirapitinga (Piaractus brachypomus): malhadeira com malha de 90 (noventa) a 100 (cem) milímetros, medidos entre nós opostos;

V - Acará (Astronotus spp.) e piranha (Serrasalmus spp.): malhadeira com malha de 40 (quarenta) a 50 (ciquenta) milímetros, medidos entre nós opostos.

Art. $8^{\circ}$ É proibido o uso dos seguintes petrechos e métodos de pesca.

I - redes de arrasto e de lance;

II - curral;

III - timbó;

IV - tapagem;

V - batição;

VI - explosivos ou substâncias que, em contato com a água produzam efeitos semelhantes.

Art. 11. A pesca em caráter científico é permitida, desde que devidamente autorizada pelos órgãos competentes.

No Acordo de Pesca do Setor Capivara, no artigo $7^{\circ}$, também se observa regra para disciplinar o acesso às áreas abrangidas, limitando-se a utilização apenas às populações locais pelos critérios de proximidade e territorialidade:

Art. $7^{\circ}$ Pescadores de outras comunidades, da sede municipal de Alvarães e Tefé, quando forem capturar peixes para subsistência nos lagos do acordo, deverão obter a permissão para acesso fornecida pela liderança da comunidade mais próxima ao lago pretendido para pesca.

Existem, ainda, no Acordo de Pesca do Setor Capivara, regras de fiscalização, no artigo 10, em regime de monitoramento com a participação de órgãos ambientais, da sociedade civil e dos pescadores urbanos das Colônias Z-4 de Tefé e Z-23 de Alvarães; e de punição, no artigo 11, em que se dá a remessa à legislação pertinente, não contemplando a possibilidade de transferência dessa atribuição para o particular:

Art. 10. A fiscalização, vigilância e monitoramento dos ambientes aquáticos previstos neste Acordo far-se-ão, através de Mutirões Ambientais, mediante parceria 
entre os órgãos do Sistema Nacional de Meio Ambiente - SISNAMA, de âmbito estadual e municipal e a sociedade civil organizada.

$\S 1^{\circ} \mathrm{O}$ período de vigilância será de 06 (seis) dias, sendo 05 (cinco) dias de vigilância e 01 (um) dia para deslocamento da equipe.

$\S 2^{\circ} \mathrm{A}$ atividade de vigilância começa às 12 (doze) horas do dia de deslocamento e encerra às 12 (doze) horas do sexto dia.

$\S 3^{\circ}$ As equipes serão formadas por no mínimo $10(\mathrm{dez})$ pessoas por período de vigilância.

Parágrafo único. Os pescadores urbanos das Colônias Z-4 de Tefé e Z-23 de Alvarães integrarão os grupos formados pelas comunidades.

Art. 13. Aos infratores da presente Instrução Normativa serão aplicadas as penalidades previstas na legislação vigente e demais normas complementares.

Identificadas as regras do Acordo de Pesca do Setor Capivara, avança-se a seguir sobre a solução do problema proposto.

\section{A CULTURA CONTRATUALISTA E OS DIREITOS COLETIVOS}

Os acordos de pesca, mesmo quando instituídos fora de espaços territoriais protegidos, contemplam regras de acesso e uso que limitam direitos individuais, tanto de integrantes da comunidade ribeirinha quanto de terceiros não participantes.

Porém, tais regras têm validade para vincular terceiros que não participaram do acordo de pesca? Como um acordo firmado por lideranças locais do ramo pesqueiro e dirigentes de órgãos pode impor comportamentos sem que dele se tenha feito parte?

Não há dúvida de que, acaso instituídos no âmbito de unidades de conservação, tais acordos de pesca poderiam vincular terceiros, até porque nestas áreas especialmente protegidas existiria um regime especial antecedente, o que não acontece, entretanto, no Acordo de Pesca do Setor Capivara.

Para a solução deste problema, é preciso compreender a reestruturação do Estado moderno e a categoria dos direitos coletivos, como expressão de uma titularidade difusa, afastando-se de uma concepção clássica e inadequada.

\subsection{A Cultura Contratualista}

A teoria contratualista clássica repousa no princípio da obrigatoriedade do contrato, que sintetiza a máxima de que o contrato faz lei entre as partes. Esta construção decorre diretamente da autonomia da vontade, pelo que a imposição aos efeitos do contrato deriva do fato de as partes terem aceito o seu conteúdo.

Por causa disso, os contratos são marcados pela relatividade, onde apenas as partes estão vinculadas ao cumprimento de suas disposições, não alcançando, em regra, terceiros não 
participantes. Pela autonomia da vontade, somente quem livremente concordou com as regras do contrato permanece obrigado.

Destarte, Roppo (2009, p. 129) pontua:

\footnotetext{
Compromissos ou mesmo efeitos negativos sobre o património das pessoas podem derivar da vontade das próprias, ou eventualmente da lei, mas já não da vontade de outros sujeitos.

Este princípio - dito da relatividade dos efeitos contratuais - exclui que a posição jurídica de um sujeito possa ser juridicamente atingida e lesada por um contrato celebrado entre outros sujeitos.
}

Esta é uma teoria assentada no pensamento tradicional de que o contrato constitui exclusivamente um instrumento de circulação de riquezas. Seria uma relação jurídica obrigacional, com eficácia patrimonial, para a satisfação de interesses dos participantes.

Porém, isso não é compatível com a sociedade atual. Os seus bens difusos em nada se assemelham com os efeitos econômicos que se esperam de um contrato particular. Nesse quadrante, o contrato, assim como o Estado moderno que o criou, deve ser redimensionado.

No particular, o Acordo de Pesca do Setor Capivara, por regulamentar bem jurídico de maior extensão, de titularidade plural, não pode ficar adstrito a essa visão clássica.

\subsection{Os Direitos Coletivos}

Ao longo dos anos, o Estado moderno sofreu várias alterações. Com o Estado do Bem Estar Social, admitiram-se novos conceitos no Direito, que passou a ser percebido sob um viés mais prestacional.

Nesse contexto, surge uma nova categoria de direitos. "São os direitos da sociedade, que interferem, alteram e modificam a relação jurídica do sujeito com o objeto de seu direito" (SOUZA FILHO, 1997). Cuida-se de direitos coletivos, que devem ser garantidos pelo Estado mediante prestações positivas, e não negativas, isto é, de não intervenção.

Estes direitos, previstos na Constituição Federal, possuem uma titularidade plural, pertencente a todos, não individualizada. Não se confundem com a simples soma de titularidades individuais, como os direitos de associação, muito menos com os direitos individuais. Eles pertencem às comunidades tradicionais, às populações ribeirinhas e à sociedade.

Sem dúvida, o bem ambiental é um exemplo desses direitos coletivos. Consoante a Constituição Federal, todos têm direito ao meio ambiente ecologicamente equilibrado. Esclarece Souza Filho (1997) que "ele mesmo como bem individualizado faz parte, integra um 
patrimônio - público ou particular -, mas há, do ponto de vista da sociedade, uma titularidade difusa que altera sua essência".

Em razão disso, os direitos coletivos também não correspondem a uma função social à propriedade, como se fossem uma limitação a um direito individual pré-existente (SOUZA FILHO, 1997). Isso porque ocorre a alteração da própria essência do direito, agora transindividual.

Conforme Souza Filho (1997), "são verdadeiro direito real coletivo sobre a coisa alheia, com todas as características dos direitos reais, oponível erga omnes e diretamente relacionados a um bem jurídico".

Nesse campo, onde há um choque entre direitos coletivos e individuais, é perceptível que o modelo de Estado moderno, embasado no contratualismo clássico, em que o contrato apenas instrumentaliza transações econômicas, está ultrapassado e precisa ser reestruturado para comportar e proteger esses novos direitos da sociedade, superando a dicotomia público e privado.

Em iguais termos, conclui Souza Filho (1997):

\begin{abstract}
Quando dizemos, porém, que existe direito à preservação e manutenção da biodiversidade, por exemplo, assim, sem adjetivos, fica difícil dizer que seja um direito dos homens, se parecendo muito mais a um dever. E se é um dever a quem corresponde o direito? Porque ainda que se possa dizer que interessa ao homem a manutenção da biodiversidade na terra, não se condiciona a sua existência à imediata satisfação das necessidades humanas, de tal sorte que a preservação, como direito, fica estranha no sistema dicotômico do direito moderno.
\end{abstract}

Estas reflexões proporcionam o substrato teórico necessário às considerações a seguir delineadas sobre a validade do Acordo de Pesca do Setor Capivara, o qual, por expressar direitos coletivos, deve ser oposto contra terceiros não participantes, mesmo não contemplado em um espaço territorial especialmente protegido.

\title{
5 A VALIDADE JURÍDICA DO ACORDO DE PESCA DO SETOR CAPIVARA CONTRA TERCEIROS NÃO PARTICIPANTES
}

A validade é a qualidade do que é válido ou legítimo. Conforme Silva (1997, p. 453), o ato é válido quando não viciado, nem atacado de defeito, que o torne nulo ou ineficaz.

A discussão central do trabalho está assentada no questionamento da validade jurídica do Acordo de Pesca do Setor Capivara, no Município de Maraã, que não se situa em uma área especialmente protegida pelo poder público, contra terceiros não participantes. 
Como estudado, os acordos de pesca são normas criadas pelas comunidades e colônias ribeirinhas, para o controle da pesca em uma determinada região, no interesse da manutenção dos estoques pesqueiros, podendo prever quatro tipos de regras: regras de acesso, uso, punição e fiscalização.

O Acordo de Pesca do Setor Capivara estabelece regras de acesso que delimitam as áreas de pesca, excluindo terceiros estranhos, em atendimento a critérios de territorialidade e proximidade, bem como regras de uso que estabelecem modos e quantitativos para a prática da pesca na região.

A título de exemplo, para a pesca nos lagos de manutenção do Setor Capivara, é permitida a utilização de duas malhadeiras com, no máximo, cem metros de comprimento, para cada pescador, mas são proibidas caixas de isopor superior a cinquenta litros. Tais normas restringem direitos de outros pescadores, comerciais ou não.

Apesar disto, estas regras são plenamente válidas contra terceiros que não participaram do Acordo.

O fundamento está na circunstância de que estes instrumentos refletem os conhecimentos e práticas de uma população ribeirinha. Não constituem normas concebidas e impostas unilateralmente, mas consensuais, produzidas a partir de um procedimento participativo envolvendo toda a comunidade.

Assim, os acordos de pesca, mesmo fora de áreas protegidas, materializam direitos coletivos reais, de titularidade plural, entre eles a preservação do meio ambiente ecologicamente equilibrado e a proteção dos conhecimentos tradicionais. Ou seja, não configuram apenas a soma de interesses de certo grupo, mas de toda a comunidade da região.

Por tal motivo, entre as suas características, não podem ser instituídos benefícios em favor de certos grupos em detrimento de outros, devendo as restrições serem aplicadas a todos os interessados, além do que o procedimento de regulamentação exige a ampla participação das populações atingidas.

Nesse caminho, a visão contratualista clássica de que apenas as partes estão vinculadas ao cumprimento de suas disposições é absolutamente equivocada para a compreensão dos acordos de pesca, que traduzem uma dimensão transindividual.

Hoje, a preservação do meio ambiente e a defesa dos conhecimentos tradicionais das são indiscutivelmente direitos coletivos, que justificam a limitação de direitos individuais. Não se admite mais que os interesses de alguns grupos afrontem bem coletivo real, pertencente a todos, estabelecido nesses acordos de pesca. 
Também não se pode esquecer que os acordos de pesca, inclusive em áreas não protegidas, como aconteceu com o Acordo do Setor Capivara, são reconhecidos pelo poder público mediante atos administrativos. Destarte, ostentam a legitimidade conferida pelo Estado para impor obrigações a terceiros não participantes.

Portanto, o Acordo de Pesca do Setor Capivara, ao expressar direitos coletivos dos comunitários, ribeirinhos, pescadores profissionais e representantes das comunidades ribeirinhas do São Francisco, São José, Bom Jardim, Santa Rosa (Paraná Capivara), São João e Caburini de Baixo, localidade Teena (Rio Solimões), Colônia de Pescadores Z-4 de Tefé, Colônia de Pescadores Z-23 de Alvarães, tem validade jurídica contra todos.

\section{CONCLUSÃO}

A região amazônica é palco de constantes conflitos socioambientais pesqueiros. Como efeito, as populações ribeirinhas passaram a definir normas consensuais para o controle dos recursos pesqueiros na região, materializadas em acordos de pesca dotados de regras de acesso e uso desses bens.

Porém, alguns acordos de pesca foram instituídos fora de áreas protegidas, sem um regime de administração anterior, pelo que fica a indagação se as regras ali previstas seriam válidas contra terceiros não participantes. Este é o caso do Acordo de Pesca do Setor Capivara, reconhecido na Instrução Normativa SDS n. 03/2014.

A partir de um referencial socioambiental, é possível reconhecer a validade destas regras mesmo contra terceiros. Isso porque o direito em análise não se restringe a uma visão contratualista nem à simples soma de direitos individuais. Os acordos de pesca expressam os conhecimentos tradicionais e a proteção do meio ambiente equilibrado, direitos coletivos estes que exigem um novo redimensionamento.

Esta conclusão alcança o Acordo de Pesca do Setor Capivara, no Município de Maraã. Mesmo não inserido em uma área especialmente protegida, os objetivos das regras que institui, no interesse da manutenção dos estoques pesqueiros e das populações ribeirinhas, justificam sua validade contra terceiros, que podem ser sancionados, acaso descumprido.

\section{REFERÊNCIAS}

ACSELRAD, Henri. Conflitos ambientais - a atualidade do objeto in Conflitos Ambientais no Brasil. ACSELRAD, Henri (org.), Rio de Janeiro: Relume Dumará: Fundação Heinrich Boll, 2004, pp. 7-11. 
AGUIAR, Denilson Melo de. Por uma alteridade jurídica nos conflitos socioambientais pesqueiros: uma análise sobre a Comunidade Santo Antônio do Rio Urubu - AM. In: Revista de Direito Ambiental da Amazônia, Hiléia, ano 7-8 n. 13-14, dez/2009-jan/jun/2010. Manaus: Edições da Universidade do Estado do Amazonas.

ALMEIDA, Bruna G. D'. Os Acordos de Pesca na Amazônia: uma perspectiva diferenciada da gestão das águas. Disponível em:

$<$ http://www.conpedi.org.br/manaus/arquivos/anais/recife/direito_ambiental_bruna_almeida.p df >. Acesso em: 26 jul. 2015.

ALMEIDA, Dean Fabio Bueno. Direito Socioambiental: o significado da eficácia e da Legitimidade. 1. ed. Curitiba: Juruá, 2003.

BRASIL. Constituição da República Federativa do Brasil. Congresso Nacional, Brasília, 1988.

. Lei n. 11.959, de 29 de junho de 2009. Presidência da República, Brasília, 2009.

Instituto Brasileiro do Meio Ambiente e dos Recursos Naturais Renováveis

(IBAMA). Instrução Normativa n. 29, de 31 de dezembro de 2002. . Disponível em: < http://www.direito.mppr.mp.br/arquivos/File/Instrucao-Normativa-n-29-2002.pdf >. Acesso em: 18 jul. 2015.

Secretaria de Estado de Meio Ambiente e Desenvolvimento Sustentável do Amazonas (SDS). Instrução Normativa n. 3, de 26 de junho de 2014. Disponível em: < http://www.legisweb.com.br/legislacao/?id=272045 >. Acesso em: 18 jul. 2015.

CAMARGO, Serguei Aily Franco de; SOUZA, Andrei Sicsú de; CAMARGO, Thaísa Rodrigues Lustosa de. O Direito Pesqueiro no Ordenamento Jurídico Brasileiro. In: Direito, Política e Manejo Pesqueiro na Bacia Amazônica. 1. ed. São Carlos: Rima Editora, 2012.

DIAS, Bianca Gabriela Cardoso. Conflitos ambientais e de pesca: o caso do Rio Arari e a regulamentação do acordo de pesca. $2012.117 \mathrm{f}$. Dissertação (Mestrado em Direito Ambiental) - Escola Superior de Ciências Sociais, Universidade do Estado do Amazonas, Amazonas.

EYNG, Vanessa. Instituto Mamirauá assessora acordo de pesca fora de área protegida. Disponível em: <http://www.mamiraua.org.br/ptbr/comunicacao/noticias/2014/7/19/instituto-mamiraua-assessora-acordo-de-pesca-fora-dearea-protegida/ >. Acesso em: 18 jul. 2015.

. Área fora de reserva inicia pesca manejada de pirarucus. Disponível em: < http://www.mamiraua.org.br/pt-br/comunicacao/noticias/2014/10/31/area-fora-de-reservainicia-pesca-manejada-de-pirarucus/>. Acesso em: 18 jul. 2015.

FERREIRA, Efrem Jorge Gondim. Recursos pesqueiros Amazônicos: uma análise conjuntural. In: Grupo de Estudos Estratégicos Amazônicos (GEEA). Tomo II. Manaus: INPA, 2009.

FRANCO, Vera Helena de Mello. Teoria Geral do Contrato: confronto com o direito europeu futuro. 1. ed. São Paulo: Editora Revista dos Tribunais, 2011. 
ROPPO, Enzo. O contrato. Tradução de Ana Coimbra e M. Januário C. Gomes. 1. ed. Coimbra: Edições Almedina, 2009.

RUFFINO, M.L. (Org.). A pesca e os recursos pesqueiros na Amazônia brasileira. Manaus: Ibama/ProVárzea,2005.

SILVA, De Plácido e. Vocabulário Jurídico. Rio de Janeiro: Forense, 1997. 4 v.

SOUZA FILHO, Carlos Frederico Marés. Os direitos invisíveis. Disponível em: < http://www.anpocs.org/portal/index.php?option=com_docman\&task=doc_view\&gid=5240\&I temid=360 $>$. Acesso em: 18 jul. 2015.

WWF BRASIL. PRÓ-VÁRZÉA. Acordos de pesca: a comunidade é quem faz. Disponível em: < http://pt.slideshare.net/zezinhocoimbra/3-cartilha-acordos-de-pesca>. Acesso em: 18 jul. 2015. 